\title{
Double Inlet Left Ventricle with Eisenmenger Syndrome in an Adult - A Case Report
}

Rahul Regi Abraham. ${ }^{1,2}$

\begin{abstract}
Background: Patient diagnosed with double inlet left ventricle (prevalent in 5 - 10 in 100,000 newborns) complicated with Eisenmenger syndrome had a median survival age of 14 years without corrective surgery. Congenital heart disease such as this is usually treated by multiple surgeries during early childhood. A surgically uncorrected case in adults is not of common occurrence. Further, generalized itching after coming in contact with water (aquagenic pruritis) presented an interesting conundrum to treat. Case: A 29-year-old patient in India presented at a primary health care center with a history of difficulty breathing and discoloration of extremities since birth. He also gave a history of itching which commonly occurred after taking bath, hemoptysis and history of turning blue in color after birth. Patient had received no treatment besides regular phlebotomies. On examination, there was grade IV clubbing and conjunctival congestion. Cardiovascular examination revealed an enlarged heart, heaving apex beat and a pan-systolic murmur. A provisional diagnosis of a congenital cyanotic heart disease was made. Investigations revealed hemoglobin of $16.8 \mathrm{~g} / \mathrm{dl}$. X-ray and electrocardiogram showed hypertrophy of the ventricles. An echocardiogram showed double inlet left ventricle with L-malposed vessels but without pulmonary stenosis. A final diagnosis of congenital heart disease; double inlet left ventricle, L-malposed vessels without pulmonary stenosis, Eisenmenger Syndrome and absolute erythrocytosis was made. Patient was advised for further management with a cardiologist in a tertiary center but the patient did not follow up. Conclusion: Unlike in high-income countries where most congenital heart diseases are detected and dealt with at birth whereas low-and middle-income nations often have to deal with cases that present much later and should often be included in the differential diagnosis. Inability to follow up cases, centers that are poorly equipped and lack of facilities for investigations, patient's lack of medical awareness, and financial restrictions are major barriers to providing optimal treatment.
\end{abstract}

Keywords: Heart Defects, Congenital; Transposition of Great Vessels; Polycthemia; Eisenmenger syndrome; Pruritis (Source: MeSH-NLM).

About the Author: Rahul Regi Abraham is a internal in Dr. B. R. Ambedkar Me dical College, and the Rajiv Gandhi University, in India.

Editor: Huy Ming Lim.

Submission: 2016-10-22

Acceptance: 2017-05-21

Process: Peer-review

\section{Introduction}

Surviving adults with an uncorrected double inlet left ventricle (DILV) is not commonly seen ${ }^{12}$. Here we present one such case accompanied with Eisengmenger syndrome. DILV also known as "Single Ventricle" is a congenital heart defect where both the left and the right atrium opens into the left ventricle (Compare figure $1 a$. of normal heart and $1 b$. of a heart with DILV). The right ventricle is either hypoplastic or does not exist. It has a prevalence of 5-10 in 100,000 new-borns ${ }^{3}$. DILV comprises about $1 \%$ of all congenital heart disease (CHD) 4. Median survival of surgically uncorrected patients is about 14 years ${ }^{5}$. Eisenmenger's syndrome (ES, Eisenmenger's reaction or tardive cyanosis) is a process by which the left-to-right shunt caused by a congenital heart defect in a foetus causes an increased flow through the pulmonary vasculature causing pulmonary hypertension ${ }^{6}$ which over time causes increased pressure in the right side of the heart and reverses the shunt into a right-to-left shunt. An informed consent was taken from the patient for the purposes of this case report.

\section{The Case}

The patient is a 29-year-old male from India, born in rural Kerala, came to an NGO (primary level health care center, with free consultation) with chief complaints of breathlessness on exertion since many years and increased discoloration of fingers, tongue and limbs since the past 3-4 months.

- Breathlessness: Grade two (New York Heart Association classification) - Slight limitation of physical activity. Ordinary physical activity results in fatigue, palpitation, dyspnoea. Patient can walk for $0.5 \mathrm{Km}$ before the onset of dyspnoea. It is exaggerated on sustained physical activity and is relieved on rest. There was a progressive increase in breathlessness from the time of his birth till the patient was 10 years of age afterwards his symptoms have improved and currently shows no progressive increase.

- $\quad$ Bluish discoloration of tips of fingers, tongue, lips: It is present at all times. It increases on exposure to cold climates, exposure to cold water and other cold substances. This has been present since his childhood and is temporarily improved with phlebotomy.

- Itching: Started five years back. Gradual in onset. Non-progressive, continuous. Increases on taking a warm shower and relieved only after a phlebotomy.

No history of orthopnoea, paroxysmal nocturnal dyspnoea and platyopnoea, chest pain, palpitation, syncope nor edema.

He gives a history of a single episode of hemoptysis three years back which has not recurred since. Patient suffered from dengue when he was 18 years old and during laboratory investiga-

${ }^{1}$ Dr. B. R. Ambedkar Medical College, Bengaluru, India.

${ }^{2}$ Rajiv Gandhi University, India. 
Figure 1a. Normal Heart; 1. Understanding your child's heart - Double inlet ventricle (British Heart Association. 1st ed. 2016. Cited 28 November 2016. Available from: https://www.bhf.org.uk/publications/children-and-young-people/understanding-your-childsheart---double-inlet-ventricle) Reprinted with permission from British Heart Association

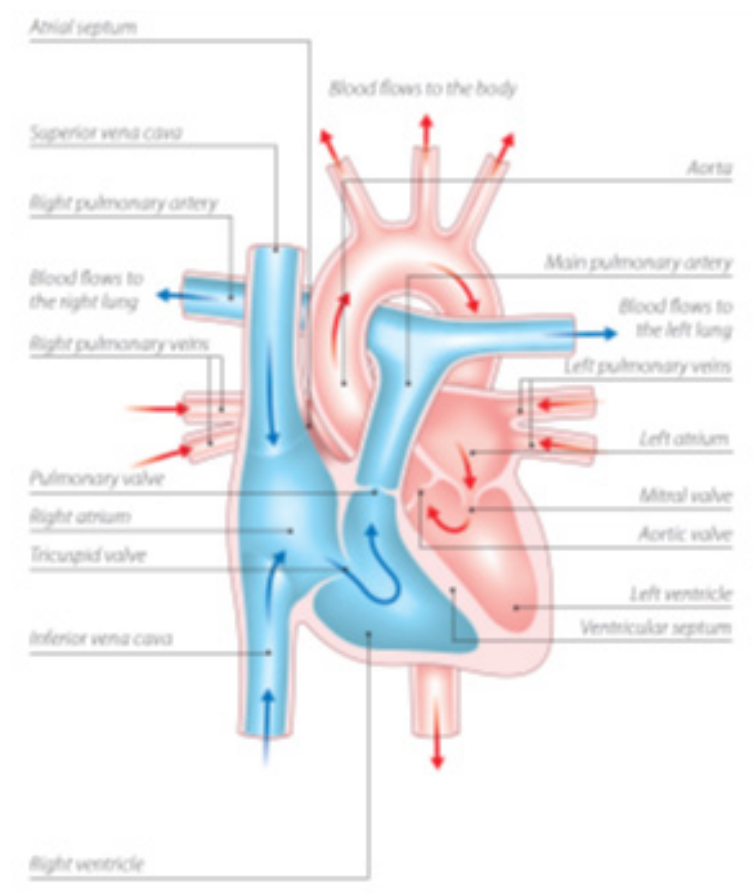

tion for the same he was found to have high hemoglobin levels and has since been asked to perform regular phlebotomies if his hemoglobin crossed $16 \mathrm{~g} / \mathrm{dl}$ (last phlebotomy in 2015). He gives history of difficulty gaining weight as a child and also history of repeated respiratory tract infections. There is no history of repeated throat infections, diabetes mellitus, hypertension, thyrotoxicosis or bronchial asthma. General examination revealed patient is moderately built and nourished (BMI: 18.51). Patient has red conjunctiva; clubbing (Grade IV); cyanosis of lips, fingers and tongue. His vital showed pulse: 92 beats per min, regular rhythm, normal in volume and character; Respiratory rate: 26 breaths/min, abdomino-thoracic respiration. Jugular venous pulse (JVP) was not raised.

\section{Systemic examination}

Cardiovascular System: Inspection (abnormal finding): Apex beat is visible in anterior axillary line in the 6th intercostal space. There are no dilated veins, scars or sinuses. Palpation: Position of apex beat is confirmed and is of heaving type. Percussion: Indicates an enlarged heart. Right border of the heart being percussed in right parasternal area. The upper border of the heart in the 3 rd intercostal space in the parasternal line. The left border of the heart in the 4 th intercostal space. Auscultation: S1 and a loud S2 heard. Pan systolic murmur heard at the apex. Loud p2. Examination of other systems reveals no abnormalities.

At this stage a provisional diagnoses of congenital cyanotic heart disease was made with the possible differential diagnosis
Figure $1 b$. Heart with Double Inlet Left Ventricle; Understanding your child's heart - Double inlet ventricle (British Heart association. 1st ed. 2016, cited 28 November 2016. Available from: https:// www.bhf.org.uk/publications/children-and-young-people/understanding-your-childs-heart---double-inlet-ventricle). Reprinted with permission from British Heart Association

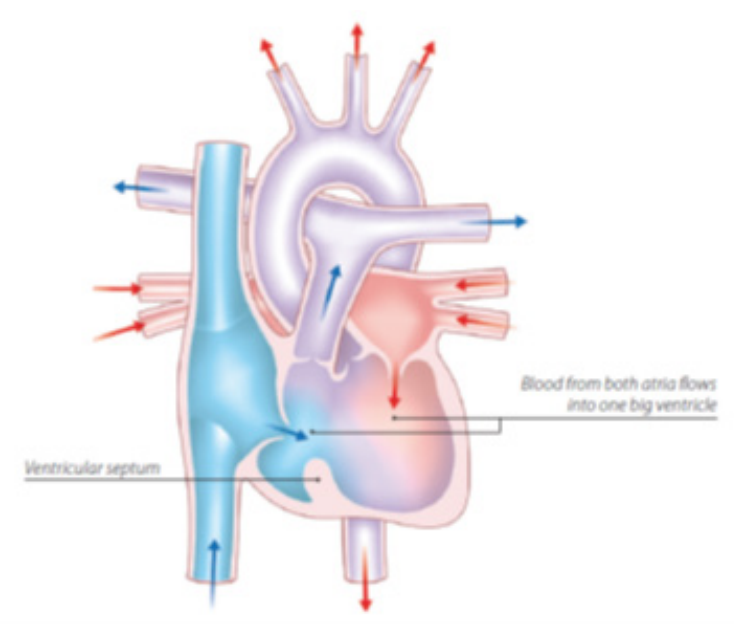

being double inlet ventricle; Tetralogy of Fallot; patent foramen ovale; atrial septal defects; atrio-ventricular septal defects; ventricular septal defects, and the persistent arterial duct.

\section{Investigations}

A review of the patient's files the patient showed that the diagnosis of double inlet left ventricle was made at a tertiary level hospital but no therapeutic interventions were performed nor regular follow ups were made. Patient explained that financial difficulties, lack of awareness for the need for follow up and absence of symptoms that severely affected daily life were why he and his family did not feel the need for regular follow up. Additional exams revealed:

i. Complete blood count: Hemoglobin: $16.8 \mathrm{gm} / \mathrm{dl}$; PCV:67.80\%; RBC:10.62 million/cu.mm

ii. Chest Radiography (Figure 2): Cardiomegaly.

iii. ECG: Sinus tachycardia, bi-atrial enlargement; left ventricular hyper trophy; probable right ventricular hypertrophy

iv. $\quad E C H O$ : Left ventricle: Dominant; Right ventricle: Left outset; Great arteries are L-Malposed with Aorta to the anterior and left from RV; Pulmonary artery posterior and right from LV; Interventricular septum: Nonrestrictive bulboventricular foramen; Aorta arch: Left sided.

A final diagnosis of congenital heart disease; double inlet left ventrice, L-malposed vessels without pulmonary stenosis, Eisenmenger Syndrome and absolute erythrocytosis was made. 


\section{Management}

The center at which the patient presented was not equipped neither with facilities to treat a cardiac case nor a cardiologist for consultation on further management strategies. The patient was counseled about the need for routine follow up treatment with a single doctor and was advice to visit a tertiary care center. Up to this day of writing this case report the patient has not visited a tertiary center and continues with occasional phlebotomies.

\section{Discussion \\ Etiology}

DILV to be genetically determined by multiple genes. Recurrence a transmission risks remain far below than that expected from medelian inheritance '. In the polygenic model, the phenotype is presumed to result from additive effects of multiple genes, interactions with other genes and environmental factors, and stochastic effects ${ }^{8}$.

\section{Pathophysiology}

In a heart with DILV blood from both the atria flow into the left ventricles from here blood flows into the pulmonary circulation through the pulmonary artery and into the systemic circulation by shunting (left to right shunt) through the bulboventricular foramen and then entering the aorta (Figure 1b). The ratio of how much blood enters each circulation depends on the ratio of vascular resistances in the two vascular beds ${ }^{8}$. This results in a left to right shunt and later on its sequelae (Figure 3 ).

\section{Prognosis}

The actuarial survival rate without definitive repair was $57 \%$ at 1 year, $43 \%$ at 5 years, and $42 \%$ at 10 years for DILV. Moodie et al reported that $70 \%$ with well-formed single left ventricles died before age 16 , with an annual attrition rate of $4.8 \%{ }^{15}$. Usual causes of death are congenital heart disease, arrhythmias and sudden death from unknown causes. A10-year mortality rate among untreated patients approached $30-40 \%{ }^{16}$. Common cause of death in these patients are hypoxemia and arrhythmia. They can also die from congestive cardiac failure, thromboembolism and massive hemoptysis.

\section{Conclusion}

Unlike high-income countries where most congenital heart diseases are detected and dealt with at birth low and middle-income nations often have to deal with cases that present much later and should often be included in the differential diagnosis.

In India there are far too many patients and too few doctors (Sudhir Anand, Victoria Fan. The health workforce in India, human resources for health observer series No.16. World Health Organization; 2016. Available from: http://www.who.int/hrh/ resources/16058health_workforce_India.pdf. Accessed June 8, 2017. The World Bank. World development indicators: Health systems. Available from: http://wdi.worldbank.org/table/2.12\#. Accessed June 8, 2017). Public health systems are overcrowded and private health care is expensive and is mostly set up in urban India as compared to rural areas. There does not exist a system in place for patient follow up after treatment or to ensure that a patient has followed up at a higher center. Most patients seek symptomatic treatment and once their acute episode has been controlled will insist on discharge despite
Figure 2. $X$-ray Chest Posteroanterior View Showing Cardiomegaly $[(A+B) / C=0.54, A=3.28 \mathrm{~cm}, B=6.83 \mathrm{~cm}, C=18.52 \mathrm{~cm}]$

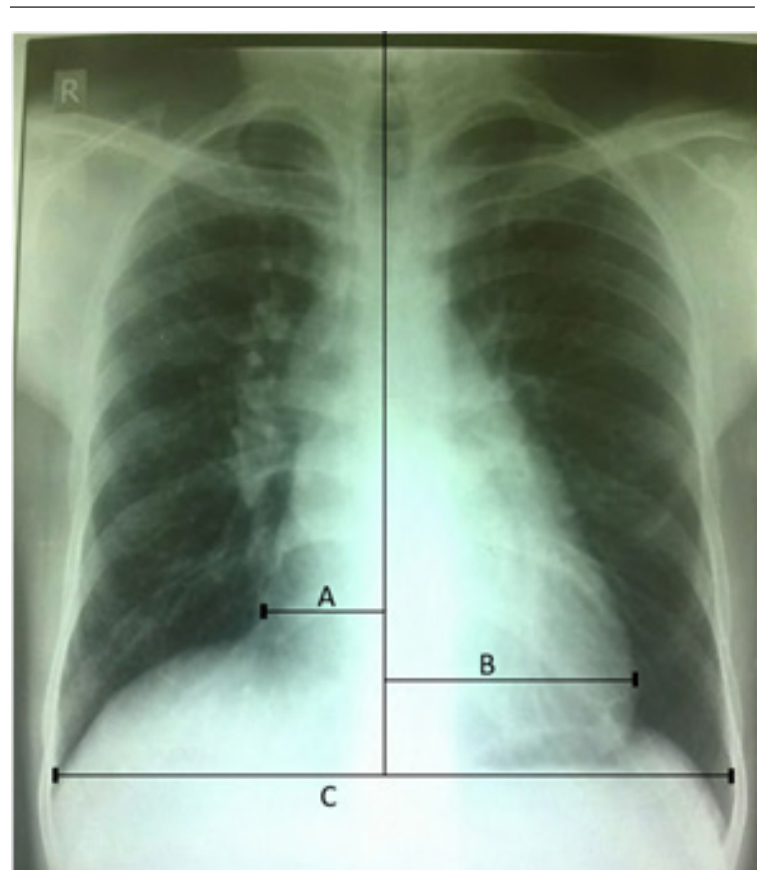

incomplete treatment of the cause. If the doctor refuses symptomatic treatment the patient will simply move on to another doctor that is willing to do so, hence compromising the health system. Financial difficulties provide another major problem; expensive treatment, investigation and drugs assure lack of adherence to treatment or failure to visit a doctor until the patient is significantly crippled. The Government should upgrade primary health centers and increase the doctor - patient ratio and implement strategies for the effective utilization of the present doctors such as increasing the prominence of primary health centers thereby decreasing the load on tertiary centers, medicines and basic scans such as the echocardiogram should be more affordable. The process for improvement of health care in India has been initiated and will require many more years to reach a level that can be compared to high-income countries.

Figure 3. Sequelae of double inlet left ventricle.

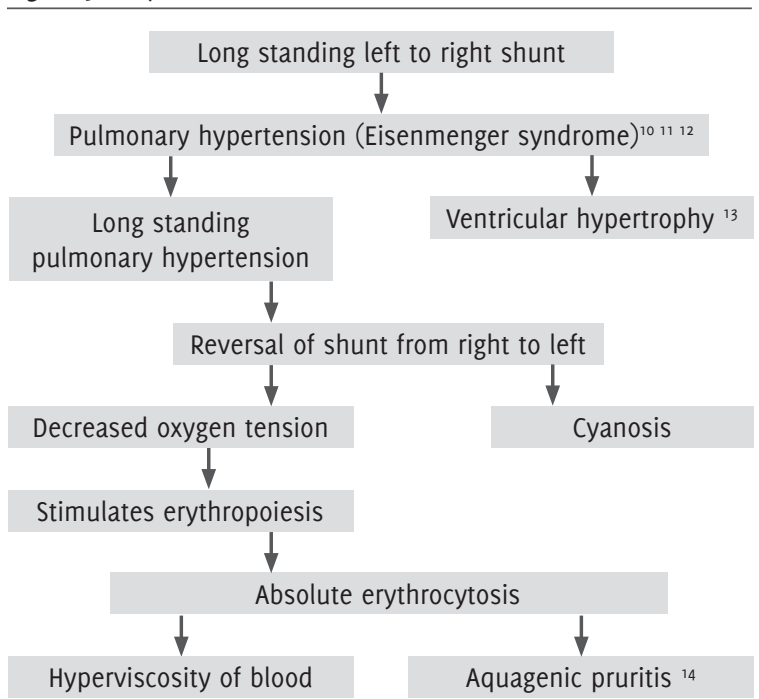




\section{References}

1. Restaino G, Dirksen MS, de Roos A. Long-term survival in a case of unoperated single ventricle. Int J Cardiovasc Imaging 2004; 20: 221-5.

2. Koito H, Ohkubo N, Suzuki J, Iwasaka T, Inada M. Prolonged survival in a patient with a single ventricle without pulmonary stenosis. Chest 1994; 106: 971-2. (Review)

3. Baldwin HS, Dees E. Embryology and physiology of the cardiovascular system. In: Cleason CA, Devaskar S, eds. Avery's Diseases of the Newborn. 9th ed. Philadelphia, Pa: Saunders Elsevier; 2011:chap 50.

4. Franklin RC, Spiegelhalter DJ, Anderson RH, Macartney FJ, Rossi Filho RI, Douglas JM et al. Double-inlet ventricle presenting in infancy: I: Survival without definitive repair. J Thorac Cardiovasc Surg. 1991;101: 767-776.

5. Moodie DS, Ritter DG, Tajik AJ, O'Fallon WM. Long-term follow-up in the unoperated univentricular heart.

Am J Cardiol 1984; 53: 1124-8.

6. Jensen AS, Iversen K, Vejlstrup NG, Hansen PB, Sфndergaard L (April 2009). "[Eisenmenger syndrome]". Ugeskrift for Laeger (in Danish) 171 (15): 1270-5.

7. Weigel TJ, Driscoll DJ, Michels VV. Occurrence of congenital heart defects in siblings of patients with univentricular heart and tricuspid atresia. Am J Cardiol. 1989; 64: 768-771.

8. Burn J, Brennan P, Little J, Holloway S, Coffey R, Somerville J, Dennis NR, Allan L, Arnold R, Deanfield JE, Godman M, Houston A, Keeton B, Oakley C, Scott 0, Silove E, Wilkinson J, Pembrey M,
Hunter AS. Recurrence risks in offspring of adults with major heart defects: results from first cohort of British collaborative study. Lancet. 1998; 351: 311-316.

9. Nelson DP, Schwartz SM, Chang AC. Neonatal physiology of the functionally univentricular heart. Cardiol Young. 2004; 14 (Suppl 1): 52-60.

10. Wood P. The Eisenmenger syndrome or pulmonary hypertension with reversed central shunt. $\mathrm{Br}$ Med J. Sep 27 1958;2(5099):755-62.

11. Vongpatanasin W, Brickner ME, Hillis LD, Lange RA. The Eisenmenger syndrome in adults. Ann Intern Med. May 1 1998; 128(9):745-55

12. Diller GP, Gatzoulis MA. Pulmonary vascular disease in adults with congenital heart disease. Circulation. Feb 27 2007; 115(8):1039-50.

13. Mohan H. Textbook of pathology. 6th ed. New Delhi: Jaypee Brothers Medical Pub; 2010:Chap 16, pg 421.

14. Abdel Naser MB, Gollnick H, Orfanos CE. Aquagenic pruritus as a presenting symptom of polycythemia vera. Dermatology. 1993; 187:130-3.

15. Moodie DS, Ritter DG, Tajik AJ, O'Fallon WM. Long-term follow-up in the unoperated univentricular heart. Am J Cardiol.1984; 53: 1124-1128

16. Diller GP, Kempny A, Inuzuka R, Radke R, Wort SJ, Baumgartner $\mathrm{H}$ et al. Survival prospects of treatment naïve patients with Eisenmenger: a systematic review of the literature and report of own experience. Heart. Sep 2014;100(17):1366-72.

\section{Acknowledgments}

Special acknowledgments go to the Dr. Ashoojit Anand, MD Community medicine and the Consultant ACCEPT.

Conflict of Interest Statement at Funding

The author has no conflict of interest to disclose.

\section{Author Contributions}

Collection and design the work/idea, collect data/obtaining results, analysis and interpretation of data, write the manuscript, critical revision of the manuscript, approval of the final version: RRA.

Cite as:

Abraham RR. Double Inlet Left Ventricle with Eisenmenger Syndrome in an Adult - A Case Report. Int J Med Students. 2017 Jan-Apr;5(1):53-56. 